\title{
What do farmers bring to market? Exploring good types, number of vendors, and founding dates by SES and race/ethnicity
}

\author{
Justin Schupp, ${ }^{\text {a* }}$ Katherine Martin, ${ }^{\mathrm{b}}$ Delia MacLaughlin, ${ }^{\mathrm{b}}$ and Eric Pfeiffer ${ }^{\mathrm{b}}$ \\ Wheaton College (MA)
}

Submitted December 28, 2020 / Revised February 28 and April 15, 2021 / Accepted April 18, 2021 /

Published online August 17, 2021

Citation: Schupp, J., Martin, K., MacLaughlin, D., \& Pfeiffer, E. (2021). What do farmers bring to market? Exploring good types, number of vendors, and founding dates by SES and race/ethnicity. Journal of Agriculture, Food Systems, and Community Development, 10(4), 143-155.

https://doi.org/10.5304/jafscd.2021.104.002

Copyright (C) 2021 by the Authors. Published by the Lyson Center for Civic Agriculture and Food Systems. Open access under CC-BY license.

\begin{abstract}
Farmers markets have been promoted as an avenue to improve access to food in neighborhoods that have been traditionally underserved by other outlets. Residents of these neighborhoods are encouraged to attend market sessions because the foods available are thought to increase access to foods that are healthier and of more variety. While previous studies have shown that farmers markets are choosing to locate in underserved areas, little research has examined how often this is occurring and what these markets offer to customers. Using survey data from 560 farmers markets across nine U.S. states and demographic data from the American Community Survey, this analysis contributes to this understanding by comparing
\end{abstract}

\footnotetext{
a * Corresponding author: Justin Schupp, Assistant Professor, Department of Sociology, Wheaton College (MA); 26 East Main Street; Norton, MA 02766 USA; +1-508-286-5775; schupp_justin@wheatoncollege.edu

b Undergraduate Research Assistant, Wheaton College (MA)
}

and contrasting the founding years, number of vendors, and types of goods available at markets by neighborhood socio-economic status and racial/ethnic composition. Results show a more recent growth of farmers markets in low-income neighborhoods when compared to more affluent neighborhoods and a relative similarity of growth when looking at racial and ethnic composition. However, the types of goods available and number of vendors are significantly lower in low socioeconomic status and high racial and ethnic minority neighborhoods when compared to more affluent and whiter neighborhoods. This suggests that there is continued and increasing farmers market presence in areas traditionally underrepresented, but that there is more work to be done to increase

\footnotetext{
Disclosures

The data collection instruments and procedures utilized for the farmers market key agent survey were reviewed and approved by the Wheaton College (MA) Institutional Research Board. The authors declare no conflicts of interest associated with this research.
} 
the number of vendors present and the diversity of offerings at these markets.

\section{Keywords}

Farmers Markets, Race and Ethnicity, Socio-

Economic Status, Inequality, Food Access

\section{Introduction and Literature Review}

Issues of disproportionately low access to food in neighborhoods with high proportions of lowincome and racial and ethnic minorities have been well documented (Eisenhauser, 2001; Jones \& Bhatia, 2011; Larsen \& Gilliland, 2009; Lowrey et al., 2016; Morland et al., 2002; United States Congress, 1992). Chief among these issues has been the diminishing access to affordable healthy foods, especially for children and those utilizing social support programs, and the documented loss of traditional food purchasing outlets, such as grocery stores (Freedman et al., 2018; Morales, 2011; Ogden et al., 2012; Slocum, 2007). Numerous organizational and policy initiatives have been proposed as solutions to fill this gap, including modifying food distribution systems and increasing and diversifying the outlets found in these neighborhoods (Markowitz, 2010; Wiskerke, 2009). Among the proposed solutions of increasing food purchasing points has been the development of direct producer-to-consumer markets (Feenstra, 2002; Hinrichs, 2000). Farmers markets have been suggested as a promising method of direct marketing to contribute to increasing food access (Gillespie et al., 2008). This promise is based upon farmers markets' documented ability to provide diversified and healthy foods options and the low start-up and operational costs needed for market sessions, compared to brick-and-mortar alternatives (Govindasamy et al., 1998; Leiper \& Clarke-Sather, 2017; Schupp, 2017).

In absolute numbers, the number of farmers markets in the U.S. has increased significantly in recent decades (Archambault et al., 2020). For example, the number of markets registered in the U.S. Department of Agriculture (USDA) farmers market directory increased from about 2,000 in 1994 to more than 8,600 in 2019--a 330\% increase in 25 years (USDA, n.d.-a, n.d.-b). In addition to fulfilling some demand for healthy foods, this growth has been attributed to farmers markets contributions to building stronger neighborhood communities and putting a larger proportion of food dollars into the pockets of farmers (Freedman et al., 2018; Hergesheimer \& Kennedy Huddart, 2010; Hinrichs, 2000; Kirwan, 2004). During this time of unprecedented growth, research has looked into the attempts of farmers markets to spread to neighborhoods that have traditionally been underserved by food outlets, such as low-income and more racially and ethnically diverse neighborhoods (Dimitri et al., 2015; Evans et al., 2012; Jilcott Pitts et al., 2015; Lowery et al., 2016; Roubal et al., 2016). Results have been mixed, but the movement of farmers markets into these neighborhoods has been hailed as a victory by many, including residents, food justice proponents, and academics (Markowitz, 2010; Ruelas et al., 2012).

Although this increase in farmers markets may be a positive sign of progress, there are several gaps in our understanding of how farmers markets in these underrepresented neighborhoods compare to markets in traditionally served neighborhoods. Specifically, we do not have data on the number of farmers markets in these underserved neighborhoods, how long they have been operating, the number of vendors present on market days, and the diversity of goods for sale at these markets, beyond examining an individual farmers market or a cluster of markets within one city or county (Alkon, 2012; Lowery et al., 2016). Missing thus far is research that uses a sample that incorporates a variety of neighborhood demographic types and geographic areas. These are important facets to understand because the existing research has suggested that the length of time a market has been present in a neighborhood, the number of vendors present, and the diversity of goods for sale all significantly influence how well it can address consumer demand and issues of food access (Alkon \& McCullen, 2011; Dimitri et al., 2015; Gillespie et al., 2007). According to the existing research, farmers markets with fewer vendors and offerings are unlikely to address food demand and food access in the same way that a market with many vendors and offerings can (Hergesheimer \& Kennedy, 2010; Larsen \& Gilliand, 2009; Lowerty et al., 2016). 
This study explores this argument by examining the relationship between neighborhood demographics and the number of vendors present and types of goods available at farmers markets. The study collected data via surveys of key agents of farmers markets $(n=561)$ in nine U.S. states and combined it with demographic data from the American Community Survey (ACS) at the censustract level. Descriptive and bivariate statistics were performed to compare and contrast the number of vendors present at market day, the types of goods for sale, and founding dates of farmers markets by a neighborhood's socioeconomic status (SES) and racial/ethnic composition. The results suggest a continued and increasing farmers market presence in areas underrepresented by other outlets, but that the markets lack in their depth of vendors and robustness of types of goods when compared to neighborhoods that have traditionally hosted markets.

\section{Applied Research Materials}

An invitation to participate in an online survey was sent to key agents of farmers markets in Colorado, Connecticut, Iowa, Kentucky, Massachusetts, New Hampshire, Oregon, Rhode Island, and Vermont $(\mathrm{N}=1,026)$ via email beginning in the summer of 2018. The data were collected in two waves. The first wave included several states in the New England region, including Connecticut, Massachusetts, New Hampshire, Rhode Island, and Vermont. Given the robust response rate seen during the initial data collection and upon securing more funding, a second wave was sent to Iowa, Kentucky, Colorado, and Oregon. These states were selected to see if the results seen in the initial wave remained consistent in other parts of the U.S. The authors recognize that this sample is not representative of all of the U.S. and, as noted in the conclusion, the results of this work only directly apply to the states sampled.

The sample was built from the USDA Agricultural Marketing Service's National Farmers Market Directory available at the time of this research, lists of markets maintained by states and food organiza- tions in the sample, and farmers markets found by the authors from internet searches. Multiple datasets were used to generate a more accurate and comprehensive sample of farmers markets than using one data source, especially given the known undercount by the USDA list because it relies on farmer markets self-reporting their existence. Farmers markets that appeared in more than one source were inspected for accuracy to see if the contact information was the same. If the contact(s) information was different, the survey was sent to the most up-to-date contact(s). An individual was considered to be a key agent if they were listed as the farmers market manager, a member of the board of directors, or if listed as the person to contact with questions about the market.

The survey was designed to collect information on several different themes about farmers markets, including market demographics, organizational strategy, financial health of the market, vendor type and prevalence, and types of goods sold. The survey consisted of 56 questions that inquired both about farmers markets generally and about the specific market that the individual was a key agent for. Utilizing Dillman's (1978) suggestions for effective survey design, non-respondents received up to four reminder emails over the course of a few weeks. Any remaining non-respondents were then sent a paper copy of the survey. Since there was a potential to hear from more than one agent of the market, anytime a key agent responded, the market was marked as being surveyed and all other key agents would not receive further reminders to take the survey. If an individual market responded more than once, each survey's answers were inspected for congruency. If answers differed significantly, the research team selected the survey that was categorized as the most reliable and comprehensive representation of the market.1 The response rate over the course of data collection for the whole sample was $54.68 \%(n=561)$. Table 1 includes a breakdown of sample size and response rates by state.

Using previous work by Jilcott Pitts et al. (2015), Larsen and Gilliland (2009), and Lowery et

\footnotetext{
${ }^{1}$ Duplicate responses for a market occurred infrequently (less than $5 \%$ of the sample) and the information provided by the respondents only differed significantly a handful of times.
} 
Table 1. Sample Sizes and Response Rates Information

\begin{tabular}{lccc}
\hline & $\begin{array}{c}\text { \# of Farmers } \\
\text { Markets in State } \\
\text { (i.e. Known } \\
\text { Population) }\end{array}$ & $\begin{array}{c}\text { \# of Markets } \\
\text { responding to } \\
\text { survey (i.e. } \\
\text { Study's sample) }\end{array}$ & Response Rate \\
\hline Colorado & 86 & 15 & $17.44 \%$ \\
\hline Connecticut & 125 & 76 & $60.80 \%$ \\
\hline lowa & 155 & 97 & $62.58 \%$ \\
\hline Kentucky & 135 & 85 & $62.96 \%$ \\
\hline Massachusetts & 231 & 145 & $62.77 \%$ \\
\hline New Hampshire & 65 & 24 & $36.92 \%$ \\
\hline Oregon & 132 & 67 & $50.76 \%$ \\
\hline Rhode Island & 39 & 19 & $48.72 \%$ \\
\hline Vermont & 58 & 33 & $56.90 \%$ \\
\hline Total & 1,026 & 561 & $54.68 \%$ \\
\hline
\end{tabular}

dors at the market, respondents were asked how many vendors were present during the height of the selling season (mean 17.89/standard deviation 15.17). Answers from six respondents were removed from the analysis because the number of vendors at each were outliers (i.e., more than 5 standard deviations above the mean). Lastly, to assess the founding dates of farmers markets, the survey asked respondents for the year that the market came into existence. Since the study was interested in where recent markets emerged, markets that were founded within the past 5 years (2013-2018) were

al. (2016), the questions in the survey about types of goods available were crafted to assess the breadth and depth of goods available at the market: types of goods, number of vendors, and founding dates. The survey included questions that asked key agents to respond "yes" or "no" if any vendor sold any goods within that category at their market during the height of the selling season. For example, respondents were asked to select "yes" for the egg question if any type of egg (e.g. chicken, duck) was for sale at the market. There were 12 dichotomous questions in the survey that asked respondents about the following types of goods: fruits, vegetables, cheeses, meats, eggs, prepared goods, canned goods, mushrooms, flowers, plants, beverages, and "other," in case there were goods that did not fall into these categories. Respondents were asked if a type of good was available at the height of the selling season in an effort to standardize data collection. The researchers believed that the height of the selling season would be when the most goods would be available during a season. If a respondent noted that their market sold a particular type of good, it was coded 1 ; if not, it was coded 0 . The scores for all 12 questions were then summarized. The scores ranged from 1 to 12 (mean 8.06/standard deviation 2.70). To assess the number of ven- coded 1 to indicate they were recent and all others (2012 or earlier) were coded as 0 .

Data from the ACS 2013-2017 five-year estimates at the census-tract level were used to approximate the boundaries of a neighborhood for the analysis. While there are many different conceptualizations in the literature as to how to measure a neighborhood, using census tracts as a proxy of a neighborhood has been shown to be an effective way to do this (Apparicio et al., 2007; Coulton et al., 2013; Hillier et al., 2011; Schupp, 2017). Two variables were created from the ACS. First, using factor analysis, an unobservable latent variable measuring SES was created from five observable manifest variables in the ACS. Figure 1 shows a visual representation of the construction of SES. Three of the manifest variables were median household income, median house value, and median rent. The ACS provided each in U.S. dollars. The fourth manifest variable, education rates, was created by aggregating individual scores within the neighborhood. Possible scores were 1 (did not graduate from high school), 2 (high school graduate), 3 (some college), and 4 (undergraduate degree and above). An average was calculated by taking the sum of all individual scores divided by the number of individuals in the neighborhood. The 


\section{Figure 1. Socio-Economic Status Variable Construction}

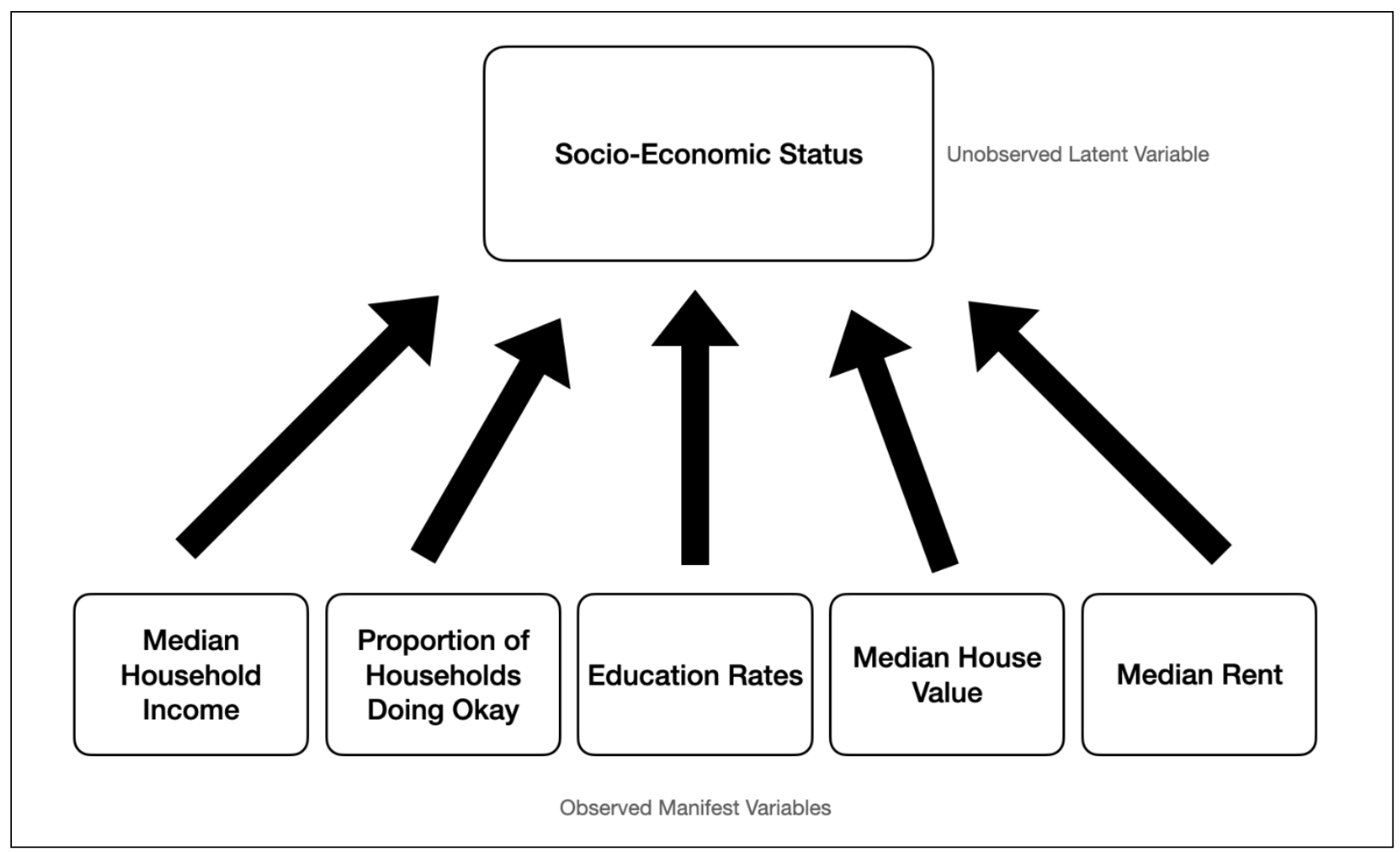

outcome was used as the neighborhood education rate. The last manifest variable was the proportion of households "doing okay" according to the ACS income-to-poverty level ratio. The ACS categorizes U.S. households into one of three economic statuses based on a ratio calculated by a household's income to the poverty level for a given household size. Ratios under 1 categorized a household as "doing poorly," ratios from 1 to 1.99 categorized a household as "struggling," and ratios 2 and above categorized a household as "doing okay." To get the proportion used in the analysis, the number of households coded as "doing okay" was divided by the number of households in a neighborhood boundary. Both Cronbach's alpha $(\alpha=.8975)$ and principal component factor (eigenvalue 3.08) analyses showed a high interrelationship among the manifest variables, suggesting the suitability for combining them into one latent variable. Since the variable was created through factor analysis, the latent variable was standardized so that the mean was 0 and standard deviation was 1 to allow for easier interpretation of individual neighborhood scores. Presented in this way, individual scores for a neighborhood SES revealed how far away that case was from the mean in standard deviation units. For example, an individual score of +1.25 would mean that case was 1.25 standard deviations above the mean, whereas -1.25 would mean that the case was 1.25 below the mean. Four neighborhoods with markets were removed from the analysis because their SES scores were more than three standard deviations above the mean and were found to skew the data substantially.

The second variable created from the ACS measured one aspect of the racial and ethnic composition of a neighborhood. Since the literature has argued about the important role that whiteness plays in farmers markets, a variable that measured the proportion of people in a neighborhood that identified as white was created. To do this, the number of residents who identified as white was divided by the total number of residents in a given tract. The result gave us the proportion of selfidentified white residents in a neighborhood. The researchers recognize there are limitations to this 
conceptualization as it does not unpack the role that individual racial and ethnic identities play and instead focuses on the effect that average neighborhood whiteness plays on increasing or decreasing the types of goods available and the number of vendors present.

STATA version 14.2 was used to join the survey data with the ACS data. Since the study was unable to collect data from all of the known farmers markets in the nine states examined, the researchers assessed the generalizability of the farmers market sample data to the population of farmers markets. In particular, the researchers wanted to know if the neighborhood characteristics of the sample represented the neighborhood characteristics of the known population of farmers markets. To do this, an independent sample mean t-test was created to test if the sample mean differed from the population mean for all of the manifest variables included in the SES variable and the race and ethnicity variable. The results suggested that the sample data did not differ statistically from the population. 2 As such, the sample data were considered representative of the demographics of neighborhoods known to have a farmers markets in the nine states surveyed.

Multiple descriptive statistics were calculated to compare and contrast markets by neighborhood SES and racial and ethnic composition, including the number of vendors present, the types of goods present, and founding dates. These analyses were performed separately for SES and racial and ethnic composition because of the aforementioned outliers and missing data in the survey. To assess if the types of goods or the number of vendors differed by SES and racial/ethnic composition, the neighborhoods were separated into deciles, meaning that the markets were separated into roughly 10 equally numbered groups by SES scores and then again by the proportion of white residents in a neighborhood. Deciles were used as a way to test and display the results in an efficient way. Deciles, similar and related to percentiles, group data into 10 equal groupings, meaning that the lowest decile $(0-10 \%)$ contains the lowest one-tenth of all cases for a variable, whereas the highest decile (91-100\%) con- tains the highest one-tenth of all cases for a variable. After separating the farmers markets into deciles, the average types of goods, average number of vendors, and percent of the newly established markets were calculated within each decile, so it could be compared to the overall sample and to the other deciles.

Several bivariate statistics were calculated to further compare and contrast the number of vendors and the types of goods by neighborhood SES and racial/ethnic composition scores. While descriptive statistics allowed us to visually inspect similarities and differences, bivariate statistics were calculated to understand if these differences were statistically significant. Four bivariate statistical tests were run. First, t-tests were performed to assess if farmers market neighborhood mean SES and mean racial/ethnic composition differed significantly from non-farmers market neighborhood mean and from the states as a whole mean. Second, Pearson chi-squared tests were run to assess if the decile means of a type of goods available differed statistically from one another for both SES and racial/ethnic composition. Statistical significance in these tests would suggest that there is an association between the two variables; however, it does not suggest a direction or strength of this association. Third, analysis of variance (ANOVA) tests were run within the SES deciles and racial/ethnic composition deciles to see if the variation of the number of vendors present differed significantly. A statically significant result would suggest the explanatory variables (SES or $\mathrm{racial} /$ ethnic composition) influence the response variable (number of vendors or the types of goods). However, a statistically significant result for this test does not indicate the direction of that effect. Last, any test outcome found to be statistically significant in the first three tests was run through bivariate regression tests run to see how the explanatory variables affect the response variables to ascertain information about the strength and direction of these relationships. To show the effect and strength of these associations, a scatterplot with a fitted regression line was constructed to visualize the prediction for the

2 The researchers do not provide the results of these tests here, but would be happy to provide them upon request. 
response variables on top of the data collected for this study.

\section{Results}

Two interesting patterns were found in the data. First, the analysis shows that the growth in farmers markets over the last five years has concentrated in neighborhoods with lower-than-average SES, whereas the growth of farmers markets was found to be more dispersed across neighborhood race and ethnicity. Second, the analysis found SES and the number of white residents in the neighborhood to be positively associated with the types of goods available for sale. The results also show a positive association between both SES and the number of white residents in the neighborhood and the number of vendors present.

\section{Population and Neighborhood Demographics}

Table 2 shows descriptive statistics for nine of the variables of interest at the population level and by if a farmers market is located in the neighborhood or not. In looking at SES, the table shows that neighborhoods with farmers markets had slightly lower SES scores $(-.147 / 1.01)$ than the states as a whole $(0 / 1)$. SES in neighborhoods without farmers markets $(.013 / .99)$ were also slightly higher than both farmers market neighborhoods and the states as a whole. Table 2 also shows that farmers market neighborhoods were found to have lower means on all five variables used to construct SES when compared to both non-farmers market and state means. When looking at the proportion of white residents in a neighborhood, Table 2 shows the population average/standard deviation to be .84/.17. Farmers market neighborhoods were found to have slightly more white residents on average (.86/.15), and non-farmers market neighborhoods were found to have slightly fewer white residents on average $(.83 / .17)$ when compared to the state mean. Collectively these two results show that farmers market neighborhoods tend to be slightly less affluent than neighborhoods without farmers markets, yet they tend to have slightly higher proportions of white residents.

Table 2 also shows the results of the t-tests described above that compared SES and the proportion of white residents by farmers market status and the entire population. The second column from the right shows the results of $\mathrm{t}$-tests between the mean of farmers market neighborhoods to the mean of the population. The last column on the right shows the results of the t-test between the mean of farmers market neighborhoods and the mean of non-farmers market neighborhoods. The results in Table 2 show that farmers market neighborhoods have significantly lower SES scores, but a significantly higher proportion of white residents

Table 2. Descriptive Statistics for Population and Neighborhoods With and Without Farmers Markets

\begin{tabular}{|c|c|c|c|c|c|}
\hline & $\begin{array}{c}\text { All } 9 \text { states } \\
\text { (mean/standard } \\
\text { deviation) }\end{array}$ & $\begin{array}{c}\text { Neighborhoods with } \\
\text { FM (mean/standard } \\
\text { deviation) }\end{array}$ & $\begin{array}{l}\text { Neighborhoods } \\
\text { without FM } \\
\text { (mean/standard } \\
\text { deviation) }\end{array}$ & $\begin{array}{l}\text { t-test population } \\
\text { vs. FM }\end{array}$ & $\begin{array}{l}\text { t-test FM vs. non- } \\
\text { FM neighbor- } \\
\text { hoods }\end{array}$ \\
\hline Socio-eeconomic Status & $0 / 1$ & $-.147 / 1.01$ & $.013 / .99$ & $12.23 * * *$ & $-3.47 * * *$ \\
\hline Median Household Income (US\$) & $\begin{array}{c}66191 / \\
31175\end{array}$ & $\begin{array}{c}60352 / \\
30682\end{array}$ & $\begin{array}{c}66693 / \\
31168\end{array}$ & & \\
\hline Average Education & $2.85 / .43$ & $2.82 / .42$ & $2.85 / .43$ & & \\
\hline Median House Value (US\$) & $\begin{array}{c}264239 / \\
183200\end{array}$ & $\begin{array}{c}256544 / \\
203133\end{array}$ & $\begin{array}{c}264900 / \\
181387\end{array}$ & & \\
\hline Median Rent (US\$) & $1054 / 413$ & $952 / 352.02$ & $1062 / 417$ & & \\
\hline Proportion Doing Okay & $.70 / .17$ & $.67 / .17$ & $.70 / .17$ & & \\
\hline Proportion White Residents & $.84 / .17$ & $.86 / .15$ & $.83 / .17$ & $-9.47 * * *$ & $4.93 * * *$ \\
\hline Types of Goods & & $8.01 / 2.7$ & & & \\
\hline Number of Vendors & & $17.89 / 15.18$ & & & \\
\hline
\end{tabular}

Note: $p$-value: * $<.05, * *<.01, * * *<.001$ 
when compared to both the entire population and to non-farmers market neighborhoods at the .001 significance level.

\section{Effect of SES and Proportion of White} Residents in Neighborbood on Types of Goods and Number of Vendors

Table 3 shows descriptive statistics of the mean types of goods and mean number of vendors by SES neighborhood deciles and by the proportion of white residents in neighborhood deciles. Results in Table 3 show a positive relationship between the mean types of goods by both SES decile and proportion of white residents decile. Though the mean types of goods ebb and flow somewhat, the overall trend is that as SES and proportion of white residents deciles increase, so do the mean types of goods. Pearson chi-squared tests show the relationship to be statistically significant for both SES $(p<0.001)$ and the proportion of white residents in a neighborhood $(p<0.01)$. Table 3 shows similar results when considering the mean number of vendors. The mean number of vendors trends upward as both SES decile and proportion of white residents decile increase. Results of the ANOVA tests show the relationship to be statistically significant between SES and vendors $(p<0.001)$, although not between the proportion of white residents and vendors. Collectively, this suggests that as SES and the number of white residents increases in a neighborhood, so do the types of goods for sale and the number of vendors at a farmers market.

Figure 2 presents scatterplots with regressions lines to illustrate the direction and strength of association between the independent variables (SES and proportion of white residents in each neighborhood) and the dependent variables (types of goods and number of vendors). The four scatterplots show positive relationships between their respective variables. Additionally, the regression coefficients, found in the second to last row of Table 3, for mean types of goods and SES $(\beta=.25)$

Table 3. Descriptive and Bivariate Statistics of Mean Types of Goods and Vendors by SES of Neighborhoods and Proportion of White Residents in Neighborhoods

\begin{tabular}{|c|c|c|c|c|c|c|}
\hline & \multicolumn{3}{|c|}{ Socio-economic Status Deciles } & \multicolumn{3}{|c|}{ Proportion of White Residents in Neighborhood Deciles } \\
\hline & $\begin{array}{l}\text { Mean Types of } \\
\text { Goods }\end{array}$ & $\begin{array}{l}\text { Mean Number of } \\
\text { Vendors }\end{array}$ & $\begin{array}{c}\% \text { Newly } \\
\text { Established } \\
\text { Markets }(n=119)\end{array}$ & $\begin{array}{l}\text { Mean Types of } \\
\text { Goods }\end{array}$ & $\begin{array}{l}\text { Mean Number of } \\
\text { Vendors }\end{array}$ & $\begin{array}{c}\% \text { Newly } \\
\text { Established } \\
\text { Markets }(n=140)\end{array}$ \\
\hline Sample Size & 549 & 517 & 493 & 561 & 529 & 504 \\
\hline Sample Mean/Total & 7.86 & 17.75 & & 7.85 & 17.89 & \\
\hline \multicolumn{7}{|l|}{ Sample Deciles } \\
\hline $0-10 \%$ & 6.58 & 9.35 & 19.33 & 6.34 & 9.79 & 9.02 \\
\hline $11-20 \%$ & 6.75 & 12.18 & 10.92 & 7.98 & 16.97 & 12.30 \\
\hline $21-30 \%$ & 7.81 & 19.68 & 6.72 & 7.57 & 19.15 & 11.48 \\
\hline $31-40 \%$ & 7.84 & 19.15 & 17.65 & 8.62 & 24.52 & 7.38 \\
\hline $41-50 \%$ & 8.20 & 18.90 & 7.56 & 8.26 & 21.14 & 10.66 \\
\hline $51-60 \%$ & 8.31 & 19.59 & 6.72 & 7.62 & 18.11 & 7.38 \\
\hline $61-70 \%$ & 8.44 & 19.41 & 7.56 & 7.90 & 18.70 & 3.28 \\
\hline $71-80 \%$ & 8.98 & 23.78 & 8.40 & 7.51 & 16.49 & 9.84 \\
\hline $81-90 \%$ & 8.40 & 19.79 & 8.40 & 8.13 & 16.97 & 14.75 \\
\hline $91-100 \%$ & 8.75 & 22.03 & 6.72 & 8.03 & 15.62 & 13.93 \\
\hline Pearson Chi2 & $170.61 * * *$ & & $45.87 * * *$ & $137.80 * *$ & & 22.47 \\
\hline ANOVA & & $5.78 * * *$ & & & $2.99 *$ & \\
\hline $\begin{array}{l}\text { Bivariate Regression } \\
\text { Coefficient }(95 \mathrm{Cl})\end{array}$ & $\begin{array}{c}0.25 * * *(.18- \\
.32)\end{array}$ & $\begin{array}{c}1.26 * * *(.84- \\
1.68)\end{array}$ & & $\begin{array}{c}2.71 * * *(1.35- \\
4.07)\end{array}$ & $\begin{array}{c}10.64 *(2.51- \\
18.76)\end{array}$ & \\
\hline
\end{tabular}

Note: p-value: $*<.05, * *<.01, * * *<.001$ 


\section{Figure 2. Scatterplots of Types of Goods/Number of Vendors by Socioeconomic Status of/Proportion of White Residents in Neighborhood}

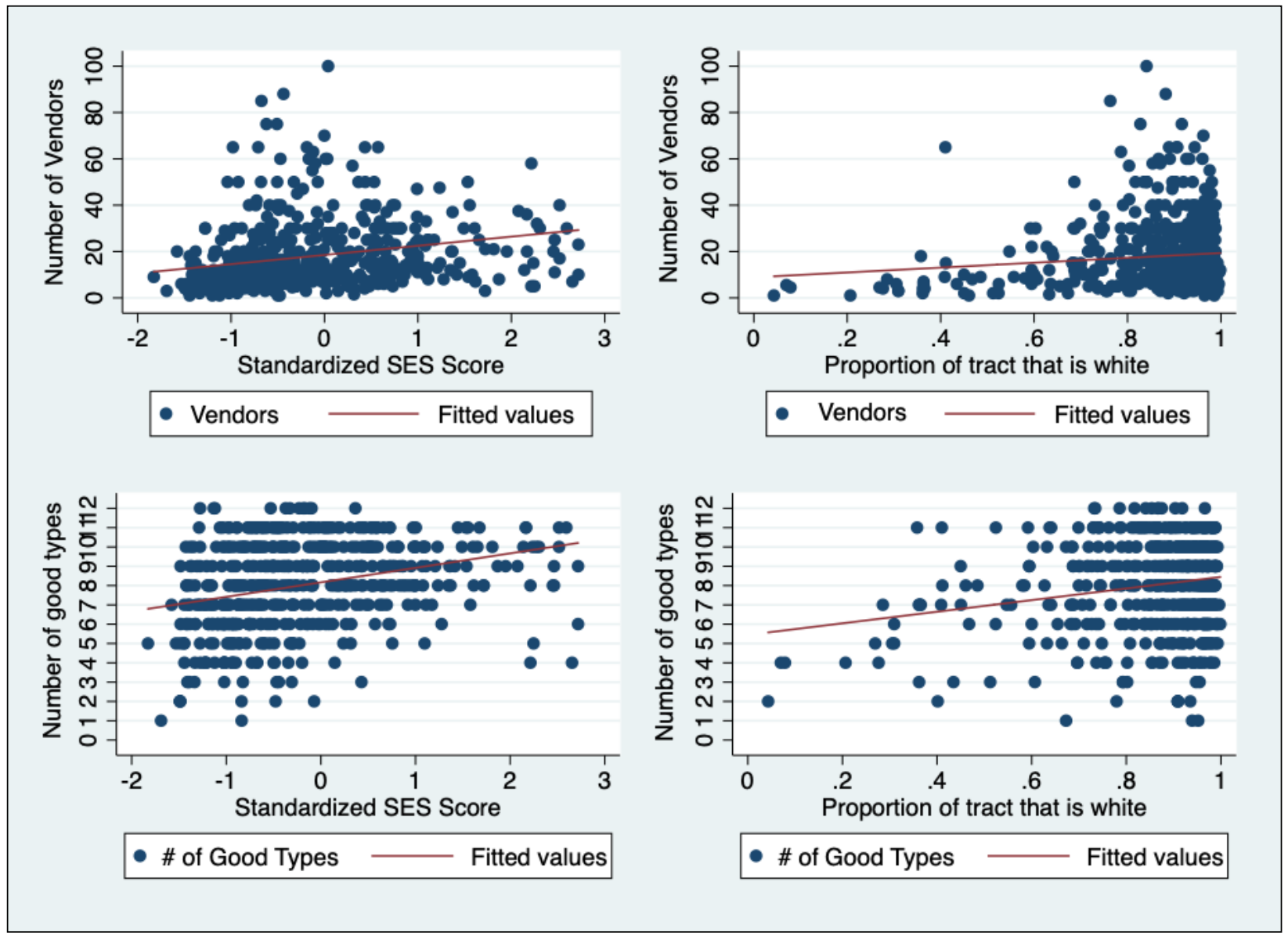

and for the proportion of white residents $(\beta=2.71)$ were both found to be statistically significant at the .001 level. Table 3 also shows the relationships between SES and the proportion of white residents with the mean number of vendors. Regression coefficients were found to be statistically significant, where SES $(\beta=1.26)$ was at the .001 level and the proportion of white residents $(\beta=10.64)$ was at the .05 level.

\section{Newly Established Markets}

The fourth and seventh columns of Table 3 show the total number of newly established markets and the percentage of newly established markets by decile. In total, $24.23 \%$ of markets $(n=119)$ were found to be newly established when analyzing the markets by the SES variable, whereas $27.78 \%$ of markets $(n=140)$ were newly established when analyzing by the race and ethnicity variable.3 Overall, the results in Table 3 show that newly established markets are disproportionately located in the lowest SES deciles. For example, of the markets founded in the last five years, $63.86 \%$ were in the bottom five deciles, including $19.33 \%$ in the first decile. In contrast, in looking at the proportion of white residents in neighborhood deciles, Table 3 shows a more variable distribution when compared to SES. Table 3 shows a large growth in some of the lowest deciles $(12.30 \%$ in the second decline and $11.48 \%$ in the third); however, it also shows a sizable percentage of newly formed markets in the top two deciles of white residents in the neighbor-

\footnotetext{
${ }^{3}$ Differences in sample sizes were because of previously mentioned outliers and missing data in the survey data.
} 
hood $(14.75 \%$ in the ninth decile and $13.93 \%$ in the tenth decile).

\section{Discussion and Conclusion}

The desire to increase access to healthy and affordable foods in underserved neighborhoods has attracted many solutions, including a variety of direct-marketing methods, such as the farmers market. While research has found that farmers markets are increasingly located in these areas, there has been a gap in examining the frequency of occurrence and, importantly, the number of vendors present and the range of goods sold. This analysis contributes to the literature by comparing and contrasting founding years, the number of vendors, and the types of goods available at markets by neighborhood SES and racial/ethnic composition. The results demonstrated that farmers markets are indeed present in neighborhoods with low SES and neighborhoods with high racial and ethnic proportions and, in fact, have experienced a disproportionately higher rate of growth in farmers markets over the last five years. However, this study also shows that the markets in these neighborhoods have significantly fewer vendors and types of goods available for purchase.

There are some limitations to this research. First, this study, though based on a large sample size, is limited in that it is cross-sectional data from nine states in the U.S. The results presented only apply directly to the states in the sample, moderately to the New England region, and at best generally to the U.S. Specifically, the researchers recognize that the nine states in this study tend to be those that are whiter than average when compared to the rest of the U.S. (United States Census Bureau, 2021). Future work that explores other parts of the U.S. could examine whether the results seen here remain consistent or reveal different trends not seen in this sample. The researchers believe that there are likely important variations between this sample and the states not included in this study that could be the focus of future research and could continue to further develop our understanding. Second, the researchers also note the surprising finding in the univariate analysis that farmers market neighborhoods were whiter yet less affluent (see Table 2). This was an unexpected finding considering the overwhelming evidence in other work that shows farmers markets being both whiter and more affluent on average. Even so, the bivariate analysis showed that the types of goods and vendors increase significantly as whiteness and affluence increased. Viewed collectively, the researchers believe that these results are similar to the preceding work in the farmers market literature. Third, the researchers recognize that our conceptualization of how to put boundaries around a neighborhood and how to measure types of goods are methodological choices that have benefits and drawbacks. The researchers contend that the benefits outweigh the drawbacks, but do not claim that this is the only way to measure a "neighborhood" and that our artificial conceptualization certainly missed out on some of the complexity and variation of this social phenomenon. Future research could further this conversation by using other conceptualizations of a neighborhood. Additionally, future research that addresses the quantity of goods within our types of goods could prove an important facet while considering food access.

Even with these data and methodological limitations in mind, this research does suggest that proponents of increasing food access through farmers markets in neighborhoods with low incomes and high racial and ethnic concentrations could celebrate some success. The results showed that farmers markets are indeed disproportionately locating new outlets in areas that have traditionally been found to be underserved by conventional food outlets, such as grocery stores, and increasingly reliant on outlets that tend to have less healthy food options, such as convenience stores (Eisenhauser 2001). However, as suggested by the results shown in Table 2, it is also important to recognize that these markets are not as well attended by vendors and that customers have fewer types of goods to pick from when compared to markets in more affluent and whiter neighborhoods.

Because this research did not explicitly explore the mechanisms that cause fewer goods and vendors, understanding why this is the case is a fruitful avenue of future research. The work of Alkon and McCullen (2011), DeLind (2011), Guthman (2011), and Slocum (2007) may prove insightful in identifying areas that one could begin to explore. In partic- 
ular, this work highlights the tendency of emerging direct food marketing to build, implement, and maintain, whether consciously or not, narratives that prioritize white and affluent privileges. These researchers highlight this as problematic because this contributes to an inflexible understanding of how to "correctly" accomplish direct marketing and direct-to-consumer sales. Given the results of this study, one is left considering that perhaps inflexible models of "how" to "best" run a farmers market may be causing issues of efficacy to emerge in spaces that have not up to this point traditionally hosted farmers markets. Both examining and encouraging farmers markets that prioritize the neighborhood's input and engagement may be of future research interest and practice based on the results of this study. While this research was able to ascertain when a farmers market was founded, who found these markets is an important question that remains. Based on these results it would be worthwhile to explore what individuals or entities are working toward bringing farmers markets to neighborhoods of color or neighborhoods with low
SES. For example, Roubal and Morales (2016) found that the city of Chicago played an instrumental role in facilitating farmers markets' ability to increase access to healthy food in communities of color.

Lastly, likely contributing to these results are the decision-making processes of the vendors as they decide which markets to participate in. Vendors, unless provided some incentive, could be less motivated to participate in markets that have, on average, a less affluent customer base in the case of low-income neighborhoods or that are in areas that have been shown to have issues in hosting successful markets, as in the case of high racial and ethnic minority neighborhoods (Dimitri et al., 2015; Evans et al., 2012; Jilcott Pitts et al., 2015; Jones \& Bhatia, 2011). This should not dissuade others from continuing to develop direct-marketing outlets in these areas, but these concerns should give those doing this work a moment of pause to consider how to best engage community members while developing markets and incentivizing producer participation.

\section{References}

Alkon, A. H. (2012). Black, white, and green: Farmers markets, race, and the green economy. University of Georgia Press.

Alkon, A. H., \& McCullen, C. G. (2011). Whiteness and farmers markets: Performances, perpetuations... contestations? Antipode, 43(4), 937-959. https://doi.org/10.1111/j.1467-8330.2010.00818.x

Apparicio, P., Cloutier, M.S., \& Shearmur, R. (2007). The case of Montréal's missing food deserts: Evaluation of accessibility to food supermarkets. International Journal of Health Geographics, 6(1), 4. https://doi.org/10.1186/1476-072X-6-4

Archambault, S., Trivette, S., Warsaw, P., \& Morales, A. (2020). Vendor variety and market sales. Journal of Agriculture, Food Systems, and Community Development, 9(2), 221-237. https://doi.org/10.5304/jafscd.2020.092.012

Coulton, C. J., Jennings, M. Z., \& Chan, T. (2013). How big is my neighborhood? Individual and contextual effects on perceptions of neighborhood scale. American Journal of Community Psychology, 51(1-2), 140-150. https://doi.org/10.1007/s10464-012-9550-6

DeLind, L. B. (2011). Are local food and the local food movement taking us where we want to go? Or are we hitching our wagons to the wrong stars? Agriculture and Human V alues, 28(2), 273-283. https://doi.org/10.1007/s10460-010-9263-0

Dillman (1978). Mail and telephone surveys_-The total design method. John Wiley and Sons.

Dimitri, C., Oberholtzer, L., Zive, M., \& Sandolo, C. (2015). Enhancing food security of low-income consumers: An investigation of financial incentives for use at farmers markets. Food Policy, 52, 64-70. https://doi.org/10.1016/i.foodpol.2014.06.002

Eisenhauser, E. (2001). In poor health: Supermarket redlining and urban nutrition. GeoJournal, 53(2), $125-133$. https://doi.org/10.1023/a:1015772503007

Evans, A. E., Jennings, R., Smiley, A. W., Medina, J. L., Sharma, S. V., Rutledge, R., Stigler, M. H., \& Hoelscher, D. M. (2012). Introduction of farm stands in low-income communities increases fruit and vegetable among community residents. Health \& Place, 18(5), 1137-1143. https://doi.org/10.1016/j.healthplace.2012.04.007 
Feenstra, G. (2002). Creating space for sustainable food systems: Lessons from the field. Agriculture and Human Values, 19(2), 99-106. https://doi.org/10.1023/A:1016095421310

Freedman, D. A., Lee, E., Ohri-Vachaspati, P., Trapl, E., Borawski, E., Bess, K., \& Flocke, S. (2018). Predictors of farmers' market shopping among people receiving Supplemental Nutrition Assistance Program benefits. American Journal of Community Psychology, 61(3-4), 488-499. https://doi.org/10.1002/ajcp.12245

Gillespie, G., Hilchey, D. L., Hinrichs, C. C., \& Feenstra, G. (2008). Farmers'markets as keystones in rebuilding local and regional food systems. In Remaking the North American Food System: Strategies for Sustainability, (pp. 65-83). University of Nebraska Press

Govindasamy, R., Zurbriggen, M., Italia, J., Adelaja, A., Nitzsche, P., \& Van Vranken, R. (1998). Farmers markets: Consumer trends, preferences, and characteristics. 52(28.3), 16-0. https://doi.org/10.22004/ag.econ.36722

Guthman, J. (2011). "If they only knew": The unbearable whiteness of alternative food. In A. H. Alkon \& J. Agyeman (Eds.), Cultivating food justice: Race, class and sustainability (pp. 263-282). MIT Press.

Hergesheimer, C., \& Kennedy Huddart, E. (2010). Farmers markets, local food systems and the social economy: A thematic literature review (pp. 1-63). BC- Alberta Social Economy Research Alliance (BALTA). http://hdl.handle.net/2149/2896

Hillier, A., Cannuscio, C. C., Karpyn, A., McLaughlin, J., Chilton, M., \& Glanz, K. (2011). How far do low-income parents travel to shop for food? Empirical evidence from two urban neighborhoods. Urban Geography, 32(5), 712729. https://doi.org/10.2747/0272-3638.32.5.712

Hinrichs, C. C. (2000). Embeddedness and local food systems: Notes on two types of direct agricultural market. Journal of Rural Studies, 16(3), 295-303. https://doi.org/10.1016/s0743-0167(99)00063-7

Jilcott Pitts, S. B., Wu, Q., Demarest, C. L., Dixon, C. E., Dortche, C. J., Bullock, S. L., McGuirt, J., Ward, R., \& Ammerman, A. S. (2015). Farmers market shopping and dietary behaviours among Supplemental Nutrition Assistance Program participants. Public Health Nutrition, 18(13), 2407-2414.

https://doi.org/10.1017/S1368980015001111

Jones, P., \& Bhatia, R. (2011). Supporting equitable food systems through food assistance at farmers markets. American Journal of Public Health, 101(5), 781-783. https://doi.org/10.2105/ajph.2010.300021

Kirwan, J. (2004). Alternative strategies in the UK Agro-Food System: Interrogating the Alterity of Farmers 'Markets. Sociologia Ruralis, 44(4), 395-415. https://doi.org/10.1111/j.1467-9523.2004.00283.x

Larsen, K., \& Gilliland, J. (2009). A farmers' market in a food desert: Evaluating impacts on the price and availability of healthy food. Health \& Place, 15(4), 1158-1162. https://doi.org/10.1016/j.healthplace.2009.06.007

Leiper, C., \& Clarke-Sather, A. (2017). Co-creating an alternative: The moral economy of participating in farmers markets. Local Environment, 22(7), 840-858. https://doi.org/10.1080/13549839.2017.1296822

Lowery, B., Sloane, D., Payán, D., Illum, J., \& Lewis, L. (2016). Do farmers' markets increase access to healthy foods for all communities? Comparing markets in 24 neighborhoods in Los Angeles. Journal of the American Planning Association, 82(3), 252-266. https://doi.org/10.1080/01944363.2016.1181000

Markowitz, L. (2010). Expanding access and alternatives: Building farmers' markets in low-income communities. Food and Foodways, 18(1-2), 66-80. https://doi.org/10.1080/07409711003708512

Morales, A. (2011). Growing food and justice: Dismantling racism through sustainable food systems. In A. H. Alkon \& J. Agyeman (Eds.), Cultivating food justice: Race, class, and sustainability (pp. 149-176). MIT Press.

Morland, K., Wing, S., \& Diez Roux, A. (2002). The contextual effect of the local food environment on residents' diets: The Atherosclerosis Risk in Communities study. American Journal of Public Health, 92(11), 1761-1768. https://doi.org/10.2105/ajph.92.11.1761

Ogden, C. L., Carroll, M. D., Kit, B. K., \& Flegal, K. M. (2012). Prevalence of obesity and trends in body mass index among US children and adolescents, 1999-2010. JAMA, 307(5), 483-490. https://doi.org/10.1001/jama.2012.40

Roubal, A. M., Morales, A., Timberlake, K., \& Martinez-Donate, A. (2016). Examining barriers to implementation of Electronic Benefit Transfer (EBT) in farmers markets: Perspectives from market managers. Journal of Agriculture, Food Systems, and Community Development, 6(3), 141-161. https://doi.org/10.5304/jafscd.2016.063.011

Roubal, A., \& Morales, A. (2016). Chicago marketplaces: Advancing access to healthy food. In J. Dawson \& A. Morales (Eds.), Cities of farmers: Problems, possibilities and processes of producing food in cities (pp. 191-212). University of Iowa Press. 
Ruelas, V., Iverson, E., Kiekel, P., \& Peters, A. (2012). The role of farmers' markets in two low income, urban communities. Journal of Community Health, 37(3), 554-562. https://doi.org/10.1007/s10900-011-9479-y

Schupp, J. L. (2017). Cultivating better food access? The role of farmers' markets in the U.S. local food movement: Cultivating better food access? Rural Sociology, 82(2), 318-348. https://doi.org/10.1111/ruso.12124

Slocum, R. (2007). Whiteness, space and alternative food practice. Geoforum, 38(3), 520-533. https://doi.org/10.1016/j.geoforum.2006.10.006

U.S. Census Bureau. (2021, April 24). 2020 demographic analysis. https://www.census.gov/newsroom/press-kits/2020/2020-demographic-analysis.html

U.S. Congress. (1992). Urban grocery gap: Hearing before the Select Committee on Hunger, House of Representatives, One Hundred Second Congress, second session, hearing held in Washington, DC, September 30, 1992. https://catalog.hathitrust.org/Record/007421271

U.S. Department of Agriculture. (n.d.-a). Local Food Directories: National Farmers Market Directory | Agricultural Marketing Service. https://www.ams.usda.gov/local-food-directories/farmersmarkets

U.S. Department of Agriculture. (n.d.-b). Number of U.S. farmers markets has nearly tripled over the last 15 years. http://www.ers.usda.gov/data-products/chart-gallery/gallery/chart-detail/?chartId=78388

Wiskerke, J. S. C. (2009). On places lost and places regained: Reflections on the alternative food geography and sustainable regional development. International Planning Studies, 14(4), 369-387.

https://doi.org/10.1080/13563471003642803 